\title{
Measurement of Blood Pressure as Cardiovascular Risk in Stable COPD Patients
}

\author{
Pervin $\mathrm{M}^{1}$, Begum $\mathrm{N}^{2}$, Ali $\mathrm{T}^{3}$, Hussain $\mathrm{D}^{4}$, Hossain $\mathrm{ME}^{5}$
}

\begin{abstract}
COPD is one of the major cause of chronic morbidity and mortality throughout the world. Among the extra pulmonary effects of COPD cardiovascular disorders are significant. Although its silent involvement is known, but little attention paid to this major comorbidity while treating these group of patients. To assess the cardiovascular risk even in stable COPD patients their systolic blood pressure (SBP), diastolic blood pressure $(D B P)$, pulse pressure $(P P)$, mean arterial pressure $(M A P)$ were observed and correlated these with the severity of airflow limitation $\left(F E V_{1}\right)$. This crosssectional study was carried out in the Department of Physiology, Bangabandhu Sheikh Mujib Medical University (BSMMU), Dhaka from January to December, 2010. For this purpose 60 (sixty) male, smoker (5-10 pack year) patients of stable COPD $(F E V, / F V C \%<0.70$; $F E V_{1} \leq 80 \%$; without any exacerbation for last 4 weeks) were randomly selected from the Out Patient Department $(O P D)$ of the Cardiovascular unit of the Department of Cardiology, BSMMU and also from a private clinic in Dhaka. On the basis of spirometric
\end{abstract}

1. Corresponding Author: Dr.Magfura Pervin Assistant Professor, Department of Physiology Tairunnessa Memorial Medical College and Hospital Gazipur, Dhaka. e-mail: dr.pervin78@gmail.com

2. Dr.Noorzahan Begum Professor, Department of Physiology Bangabandhu Sheikh Mujib Medical University Shahbag, Dhaka. e-mail: noorzahan52@gmail.com

3. Dr.Taskina Ali

Associate Professor, Department of Physiology Bangabandhu Sheikh Mujib Medical University Shahbag, Dhaka. e-mail: taskinadr@gmail.com

4. Dr.Dilroze Hussain Assistant Professor, Department of Physiology Kumudini Women's Medical College, Mirzapue, Tangail e-mail: nazmul1825@gmail.com

5. Dr.Mohammad Emran Hossain Associate Professor Department of Forensic Medicine \& Toxicology Tairunnessa Memorial Medical College and Hospital Gazipur, Dhaka. e-mail: emran73hossain@yahoo.com findings, 30 mild (group $B_{1}$ ) and 30 moderate stages (group $B_{2}$ ) of COPD patients with age 35-45 years were included in this study. In addition, 30 age, BMI, serum lipid profile and smoking status matched apparently healthy male persons were studied as control (group A). $S B P, D B P, P P$ and MAP (by sphygmomanometer and stethoscope) were measured and calculated. Data were expressed as mean $\pm S D$. For statistical analysis Independent sample t-test and Pearson's Correlation Coefficient test were performed, as applicable and $p<0.05$ was accepted as significant. Significantly $(p<0.001)$ higher $S B P, D B P, P P$ and MAP were found in moderate stage (group $B$ ) than those of control and mild stage (group $B_{1}$ ) of COPD patients. In addition, 4 types of BP were negatively correlated with FEV in moderate stage and were statistically significant for SBP $(p<0.01), P P$ and MAP $(p<0.05)$. This study reveals that, cardiovascular function status may be altered even in stable COPD and this alteration is inversely related to the severity of the disease.

\section{Key words: SBP, DBP, PP, MAP, COPD}

\section{Introduction}

COPD is a preventable and treatable disease, but once developed, this disease along with its comorbidities can not be cured totally. However, its progression and consequences can be reduced. ${ }^{1}$ Many people suffer from this morbid disease for years and die too early from its complications. It is the fourth leading cause of death in adults of USA \& also projected to be the third by $2020 .^{2-4}$ COPD is becoming a rising burden for both developed and developing countries day by day. This upsurge of the morbidity is thought to be due to urbanization, industrialization and change of profession of people from 'agriculture and fresh air' based rural communities to industry and smoking based urban settings in our country. Total burden of COPD patients in Bangladeshi population is about 6 million now. ${ }^{5}$ The pulmonary component of COPD is characterized by airflow limitation which is usually progressive and not fully reversible. Along with the pulmonary changes it also has various extrapulmonary (systemic) effects, such as raised circulatory inflammatory markers (like CRP) and polycythemia. ${ }^{6}$ These systemic effects may lead to different comorbid conditions, such as ischemic heart disease and cardiac failure. ${ }^{6-8}$ It has been proposed that about $50 \%$ death in COPD patients may result from cardiovascular cause rather than pulmonary cause itself. ${ }^{9}$ In addition, the cardiovascular risk has been reported to be independent of the effects of smoking and other factors like physical fitness, aging process, life style 
etc in this group of patients. ${ }^{10}$ However, airflow limitation and persistent low grade systemic inflammation may increase the cardiovascular risk in patients with $\mathrm{COPD}^{3}$.

Findings of some recent studies suggested that COPD itself is an important risk factor for different manifestations of cardiovascular diseases. ${ }^{11-13}$ Within these, increased systolic blood pressure (SBP) or isolated systolic hypertension has been proposed to be a direct risk factor of coronary heart disease in COPD patients. ${ }^{14}$ As the SBP is mainly influenced by stiffness of large arteries and left ventricular ejection pattern. ${ }^{15}$ Many investigators of different countries reported higher values of SBP in patients with COPD. ${ }^{2,11,13,16,17}$ In addition, DBP that is largely determined by peripheral arterial resistance and increases until middle age and then tends to fall in contrast to SBP. ${ }^{15}$ Higher values of DBP and MAP in COPD patients were also reported by different researchers. ${ }^{13}$ Again, increased pulse pressure (PP) is one of the major cardiovascular risk factor with advancing age ${ }^{14,18,19}$. Higher values of pulse pressure in COPD patients was reported by various researchers of different countries. $^{2,11,13}$ Many investigators of different countries measured different types of BP in patients with COPD and reported higher values. With the best of our knowledge various researchers studied several aspects of COPD in our country, but no reported data yet available to document the changes in SBP, DBP, PP and MAP of this group of patients. Therefore, this study was carried out to assess different types of BP as cardiovascular risk factors in male patients with stable COPD.

This study may signify the importance of screening for higher SBP, DBP, PP and MAP in order to minimize the risk for cardiovascular comorbidity in this group of patients. In addition, the outcome of this study may act as a source of background information in creating awareness to the clinicians about the cardiovascular involvement in COPD patients.

\section{Materials \& Methods}

For this study, 60 male, smoker patients of stable COPD (without any exacerbation for last 4 weeks ${ }^{12}$ ) were randomly selected from the out patient door of Cardiovascular unit of Department of Cardiology, BSMMU and also from a private clinic in Dhaka. On the basis of spirometric staging, all the patients were divided into mild (group $\left.\mathrm{B}_{1}\right)\left(\mathrm{FEV}_{1} \geq 80 \%\right.$ of predicted; $\left.\mathrm{n}=30\right)$ and moderate (group $\left.\mathrm{B}_{2}\right)\left(\mathrm{FEV}_{1}<80 \%\right.$ but $\geq 50 \%$ of predicted $\left.^{5} ; \mathrm{n}=30\right)$ stage of COPD. For comparison, 30 age (35 to 45 years), BMI (24.7 to $25.6 \mathrm{~kg} / \mathrm{m}^{2}$ ), serum lipid profile (cholesterol: 150 to $200 \mathrm{mg} \%$; TG: 50 to $150 \mathrm{mg} \%$; HDL: $>40 \mathrm{mg} \%$; LDL: $<150 \mathrm{mg} \%{ }^{20}$ ) and smoking status ( 5 to 10 pack years ${ }^{21}$ ) matched apparently healthy male persons as control (group A) were randomly selected from the community. Any subject with diabetes mellitus (Fasting plasma glucose $>7 \mathrm{mmol} / \mathrm{dl}^{22}$ ), systemic hypertension $\left(\mathrm{SBP} \geq 140\right.$ and $\mathrm{DBP} \geq 90 \mathrm{~mm}$ of $\mathrm{Hg}^{23}$ ) before the diagnosis of COPD, with any pulmonary comorbidity (e.g, bronchiectasis, pulmonary fibrosis, pneumonectomy, lobectomy) or any other systemic disease (e.g, rheumatoid arthiritis, connective tissue disorder), treatment with long term steroid or theophylline or any immunosuppressive therapy or with history of any heart disease, were excluded from the study. ${ }^{13}$ After selection, all the subjects were thoroughly informed about the aim, benefit and procedure of the study and were encouraged for voluntary participation. After their agreement an informed written consent was taken from them and was requested to attend the Department of Physiology at $7.30 \mathrm{am}$ in a fasting state on the day of examination. In addition, all of them were also instructed to abstain from tea, coffee or any type of smoking for at least 12 hours before that very day. At the examination day, their detailed personal, medical and drug history were taken and thorough physical examinations were done. All informations were recorded in a pre-fixed questionnaire. Then with all aseptic precautions $5 \mathrm{ml}$ of venous blood was collected from left ante-cubital vein to measure the serum lipid profiles and glucose. Cardiovascular status of all subjects was assessed by measuring SBP, DBP (by sphygmomanometer and stethoscope) and calculating PP and MAP.

All the data were expressed as mean \pm SD. For statistical analysis, Independent samples t-test and Pearson's Correlation Coefficient test were performed by using SPSS for windows version-12, as applicable and $\mathrm{p}<0.05$ was accepted as significant.

\section{Results}

Age and BMI were matched in all groups, as shown in Table I.

Table-I: Baseline characteristics in different groups $(n=90)$

\begin{tabular}{lll}
\hline Groups & $\begin{array}{c}\text { Age } \\
(\text { years })\end{array}$ & $\begin{array}{c}\text { BMI } \\
\left(\mathbf{K g} / \mathbf{m}^{2}\right)\end{array}$ \\
\hline $\mathrm{A}$ & $47.1 \pm 5.29$ & $25.6 \pm 2.24$ \\
$(\mathrm{n}=30)$ & $(37-55)$ & $(21-30)$ \\
$\mathrm{B}_{1}$ & $47.2 \pm 6.04$ & $25.0 \pm 2.37$ \\
$(\mathrm{n}=30)$ & $(35-55)$ & $(21-30)$ \\
$\mathrm{B}_{2}$ & $47.7 \pm 5.32$ & $24.7 \pm 3.13^{\dagger \#}$ \\
$(\mathrm{n}=30)$ & $(35-55)$ & $(19-32)$ \\
\hline
\end{tabular}

$\mathrm{A}=$ apparently healthy subjects (Control)

$\mathrm{B}_{1}=\mathrm{COPD}$ patients (mild stage)

$\mathrm{B}_{2}=\mathrm{COPD}$ patients (moderate stage)

$A$ vs $B_{1}={ }^{* *}, \uparrow, \#=$ non significant

$\mathrm{A}$ vs $\mathrm{B}_{2}={ }^{\dagger}$

$\mathrm{B}_{1}$ vs $\mathrm{B}_{2}=$ \#

Mean SBP, DBP, PP and MAP were higher in both the study groups to that of the control. However, these differences were statistically significant only in group $\mathrm{B}_{2}$ 
$(p<0.001)$ in comparison to those of control and mild stage of COPD (Table II).

Table -II: Mean \pm SD of SBP, DBP, PP and MAP in different groups $(\mathrm{n}=90)$

\begin{tabular}{|c|c|c|c|c|}
\hline \multirow{2}{*}{ Groups } & SBP & DBP & PP & MAP \\
\hline & \multicolumn{4}{|l|}{$(\mathrm{mm}$ of $\mathrm{Hg})$} \\
\hline $\begin{array}{l}A \\
(n=30)\end{array}$ & $\begin{array}{l}118.2 \pm 8.25 \\
(100130)\end{array}$ & $\begin{array}{l}76.3 \pm 5.56 \\
(70-85)\end{array}$ & $\begin{array}{l}41.8 \pm 5.49 \\
(30-50)\end{array}$ & $\begin{array}{l}90.3 \pm 6.05 \\
(80-100)\end{array}$ \\
\hline $\begin{array}{l}\mathrm{B} 1 \\
(\mathrm{n}=30)\end{array}$ & $\begin{array}{l}120.7 \pm 6.9^{*} 1 \\
(110130)\end{array}$ & $\begin{array}{l}78.5 \pm 4.38 \\
(70-85)\end{array}$ & $\begin{array}{l}42.2 \pm 4.4^{*} \\
(35-50)\end{array}$ & $\begin{array}{l}92.6 \pm 4.9^{\frac{*}{3}} \\
(83-100)\end{array}$ \\
\hline $\begin{array}{l}\mathrm{B} 2 \\
(\mathrm{n}=30)\end{array}$ & $\begin{array}{l}128.8 \pm 8.78^{\dagger \dagger} \\
(120145)\end{array}$ & $\begin{array}{l}81.3 \pm 5.5 \dot{b}^{\dagger} \dot{\# \# \#} \\
(70-90)\end{array}$ & 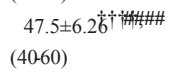 & $\begin{array}{l}97.2 \pm 6.1 \frac{1}{3} \dagger \text { †\#\# } \\
(87-108)\end{array}$ \\
\hline
\end{tabular}

$\mathrm{A}=$ apparently healthy subjects (Control)

$\mathrm{B}_{1}=$ COPD patients (mild stage)

$\mathrm{B}_{2}=\mathrm{COPD}$ patients (moderate stage)

A vs $B_{1}={ }^{* *}, \dagger, \#=$ non significant ${ }^{* *}, \dagger$, $\#$

$=$ Significance at $\mathrm{p} 0.05$

$\mathrm{A}$ vs $\mathrm{B}_{2}=\dagger^{* * *}, \dagger \dagger$, \#\#\# $=$ Significance at p 0.01

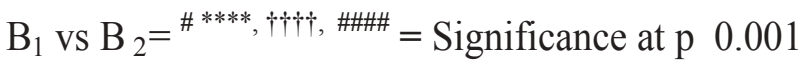

Moreover, in group $\mathrm{B}_{2}, 23(77 \%)$ and $20(66.7 \%)$

patients were with increased values of SBP and PP respectively (Table III; Figure 1).

Table -III: Frequency distribution of the subjects by increased SBP and PP in different groups $(n=90)$

\begin{tabular}{|c|c|c|c|c|c|}
\hline & \multirow{2}{*}{$\begin{array}{c}\text { Group A } \\
\text { Normal Increased }\end{array}$} & \multicolumn{2}{|c|}{ Group $B_{1}$} & \multicolumn{2}{|c|}{ Group $B_{2}$} \\
\hline & & Normal Inc & creased & Normal I & Increased \\
\hline Variables & No. $(\%)$ & No. $(\%)$ & & No. $(\%)$ & \\
\hline SBP & $30(100 \%) \quad 0(0 \%)$ & $30(100 \%)$ & $0(0 \%)$ & $7(23 \%)$ & $23(77 \%)$ \\
\hline PP & $19(63.3 \%) \quad 11(36.7 \%$ & $19(63.3 \%)$ & $11\left(36.7^{\circ}\right.$ & $10(33.3 \%)$ & $20(66.7 \%)$ \\
\hline
\end{tabular}

$\mathrm{A}=$ apparently healthy subjects (Control)

$\mathrm{B}_{1}=\mathrm{COPD}$ patients (mild stage)

$\mathrm{B}_{2}=\mathrm{COPD}$ patients (moderate stage)

Cut point for increased SBP $140 \mathrm{~mm}$ of $\mathrm{Hg}^{23}$

Cut point for increased $\mathrm{PP}>40 \mathrm{~mm}$ of $\mathrm{Hg}^{23}$

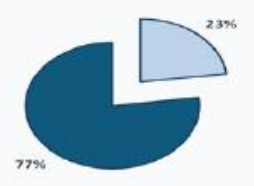

SBP

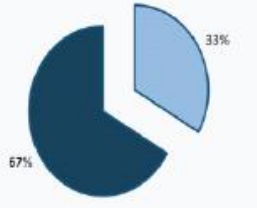

PP
口Normal

Increased

Figure-I: Frequency distribution of the subjects by increased SBP and PP in moderate stage (group $\mathrm{B}_{2}$ ) of COPD $(n=30)$ Cut point for increased SBP 140 and PP $40 \mathrm{~mm}$ of $\mathbf{H g}^{23}$
Furthermore, SBP, DBP, PP and MAP were negatively correlated with $\mathrm{FEV}_{1}$ in patients of both groups $\left(\mathrm{B}_{1}\right.$ and $\mathrm{B}_{2}$ ). Except for $\mathrm{DBP}$ all these relationships were statistically significant $(p<0.01)$ for SBP and $(p<0.05)$ for $\mathrm{PP}, \mathrm{MAP}$ in group $\mathrm{B}_{2}$ (Figure: II).
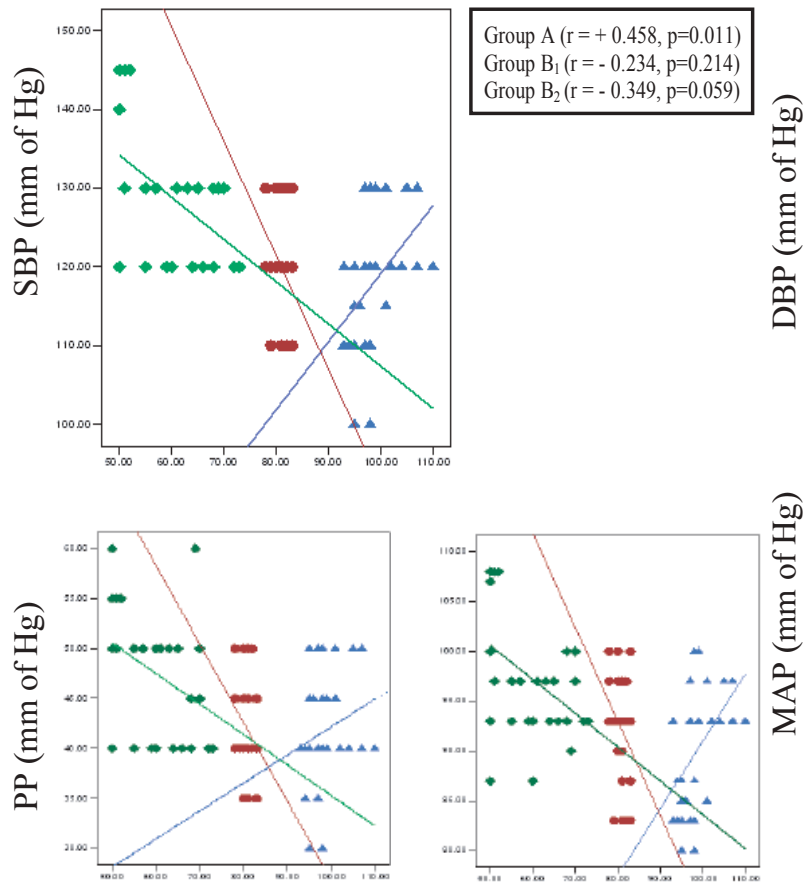

Figure- II:Correlation of SBP, DBP, PP and MAP with FEV1 in different groups $(n=90)$

\section{FEV $_{\mathbf{1}}(\%$ of predicted value)}

$\mathrm{A}=$ apparently healthy subjects (Control)

$\mathrm{B}_{1}=$ COPD patients (mild stage)

$\mathrm{B}_{2}=$ COPD patients (moderate stage)

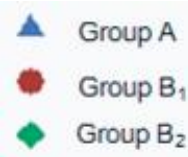

\section{Discussion}

In this study, findings of all the variables in healthy control group were within the normal range and also similar to those of the observations of various investigators of different countries abroad as well as of our country. $2,4,11,13,24$. Here, mean SBP, DBP, PP and MAP were significantly higher only in the moderate to those of the control and mild stage of COPD patients. These findings were in agreement with some other researchers abroad. 2,3,13,16 Moreover, SBP, PP and MAP were negatively correlated with $\mathrm{FEV}_{1}$ (variable of airflow limitation) in both the study groups, though the relationship was statistically significant only in moderate stage of COPD except for DBP. This finding was in agreement with several researchers of different countries. ${ }^{2,11,13}$ Although, several mechanisms regarding the changes in cardiovascular function of COPD patients have been proposed by many investigators of different countries abroad. ${ }^{1,3,25,26}$ But the exact mechanism of these changes in our study have not been clearly delineated yet. 
It has been suggested by a group of researchers abroad that the chronic airflow limitation in the COPD patients might be the causative factor for the development of chronic hypoxia. ${ }^{1}$ As a consequence there may be vasoconstriction in pulmonary circulation of this group of patients. This increment of pulmonary vascular resistance may increases the right ventricular workload.

In addition, it has also been reported that persistent low grade systemic inflammation in patients with COPD may cause excessive neutrophil elastase activity that resulting consumption of elastic fibers in the tunica media of large arteries. As a consequence there may be development of arterial stiffness (rigidity of vessel wall). ${ }^{26}$ Another group of researchers abroad proposed that elastin (core portion of elastic fiber) might be involved in the regulation of vascular smooth muscle cell functions in COPD patients. As the elastin consumed, so there may be vascular smooth muscle cell dysfunction which may contribute to the development of arterial stiffness. ${ }^{27}$ So, increased SBP and PP in COPD patients of the present study might be due to increased arterial stiffness from any of the above mentioned causes.

Increased arterial stiffness in COPD patients augments pulse pressure, left ventricular after load and myocardial oxygen demand but at the same time decreases vascular compliance, coronary circulation resulting ischemic heart disease. ${ }^{28}$ In addition to these, increased left ventricular after load promotes left ventricular hypertrophy, a recognized cardiovascular risk factor. ${ }^{29}$ Again, it has been reported by a group of researchers that there is also left ventricular diastolic dysfunction in patients with COPD. ${ }^{17}$ Thus COPD is associated with 2 to 3 fold increase in the risk of ischemic heart disease, stroke and sudden death. ${ }^{13}$ From this study, it may be concluded that the cardiovascular function status alter in stable COPD patients as evidenced by increased all types of BP and that are inversely related to the severity of airflow limitation.

\section{References}

1. GOLD Global strategy for the diagnosis, management and prevention of COPD. Report of a GOLD Consultation,2006.

2. Sabit R, Botton CE, Edward PH, Pettit RJ, Evans WD, Mc Eniery CM, et al. Arterial Stiffness and Osteoporosis in Chronic Obstructive Pulmonary Disease. Am j Respir Crit Care Med.2007;175:12591265.

3. Eickhoff P, Valipour A, Kiss D, Schreder M, Cekici L, Geyer K, et al. Determinants of systemic vascular function in patients with stable Chronic Obstructive Pulmonary Disease. Am J Respir Crit Care Med.2008;178:1211-1218.

4. Finkelstein J, Cha E, Scharf SM. Chronic Obstructive Pulmonary disease as an independent risk factor for cardiovascular morbidity. Int J Chron Obstruct Pulmon Dis. 2009; 4:337-349.
5. BOLD Burden of Obstructive Lung Disease in Bangladesh. Report On National COPD Study, October 2007, Bangladesh Lung Health Foundation.

6. Wouters EFM. Chronic Obstructive Pulmonary Disease. 5 Systemic effects of COPD. Thorax.2002;57:1067-1070.

7. Agusti AGN. Systemic effects of Chronic Obstructive Pulmonary Disease. Proceedings of the American Thoracic Society.2005;2(4):367-370.

8. Barens PJ, Celli BR. Systemic manifestations and comorbidities of COPD. Eur Respir J. 2009;33:11651185 .

9. Camilli AE, Robbins DR, Lebowitz MD. Death certificate reporting of confirmed airways obstructive disease. Am J Epidemiol.1991;133:795-800.

10. Stavem K, Aaser E, Sandvik L, Bjornholt JV, Erikssen $\mathrm{G}$, Thaulow $\mathrm{E}$, et al. Lung function, smoking and mortality in a 26-year follow-up of healthy middle-aged males. Eur Respir J.2005;25:618-625.

11. Sin DD, Man SF. Why Are Patients With Chronic Obstructive Pulmonary Disease at Increased Risk of Cardiovascular Diseases? Circulation.2003;107:15141519 .

12. Mc Allister DA, Maclay JD, Mills NL, Mair G, Miller J, Anderson D, et al. Arterial Stiffness Is Independently Associated With Emphysema Severity in Patients with Chronic Obstructive Pulmonary Disease. Am J Respir Crit Care Med.2007;176:1208 1214.

13. Mills NL, Miler JJ, Anand A, Robinson SD, Frazer GA, Anderson D, et al. Increased arterial stiffness in patients with Chronic Obstructive Pulmonary Disease: a mechanism for increased cardiovascular risk. Thorax.2008;63:306-311.

14. Franklin SS, Larson MG, Khan SA, Wong ND, Leip EP, Kannel WB, et al. Does the relation of blood pressure to coronary heart disease risk change with aging? The Framingham Heart Study. Circulation.2001;103:1245-1249.

15. Oliver JJ, Webb DJ. Noninvasive Assessment of Arterial Stiffness and Risk of Atherosclerotic Events. Arteriosclerosis, Thrombosis and Vascular Biology.2003;23: 554-566.

16. Yangfeng W, Vollmer WM, Buist AS, Tsai R, Cen R, Xigui $\mathrm{W}$, et al. Relationship between lung function and blood pressure in Chinese men and women of Beijing and Guangzhou. International journal of epidemiology.1998;27:49-56

17. Funk GC, Lang I, Schenk P, Valipour A, Hartl S, Burghuber OC. Left ventricular diastolic dysfunction inpatients with COPD in the presence and absence of elevated pulmonary arterial pressure. Chest.2008;133:1354-1359. 
18. Bortel LMABV, Boudier HAJS, Safar ME. Pulse Pressure, Arterial Stiffness, and Drug Treatment of Hypertension. Hypertension. 2001;38:914-921.

19. Daren B, Girerd X, Safar M, Cambient F, Guize L. Pulsatile versus steady component of blood pressure: a cross-sectional analysis and a prospective analysis on cardiovascular mortality. Hypertension. 1989;13:392400

20. Colledge NR, Walker BR, Ralston SH. Davidson's Principles and Practice of Medicine. 21st ed. China: Elsevier Limited; 2010.

21. Reid PT, Innes JA. Respiratory disease. In: Colledge NR, Walker BR, Ralston SH. Davidson's Principles and Practice of Medicine. 21st ed. China: Elsevier Limited; 2010: 662, 671, 676.

22. WHO Definition, Diagnosis and Classification of Diabetes Mellitus and its complication. Report of a WHO Consultation. Geneva: WHO;1999.

23. Swash M. The cardiovascular system. In: Hutchison's Clinical Methods. 20th ed. London: The WB Saunders Company; 1996: 170.
24. Ali T, Begum N, Hassan MR, Bennor KS. Effects of dietary modification on some aspects of anthropometry and pulmonary functions in patients with Chronic Obstructive Pulmonary Disease. Bangladesh J Physiol Pharmacol.2003 Jan/July;19(1/2):24-27.

25. Brooke GAB. New insight into elastin and vascular disease Trends Cardiovasc Med. 2003;13(5):176-781.

26. Stockley RA. Neutrophils and Protease/Antiprotease Imbalance. Am J Respir Crit Care Med. 1999;160: 4952.

27. Huiart L, Ernst P, Suissa S. Cardiovascular morbidity and mortality in COPD. Chest. 2005;128:2640-6.

28. Boutouyrie P, Tropeano AI, Asmar R, Gautier I, Benetos A, lacolley $\mathrm{P}$, et al. Aortic stiffness is an independent predictor of primary coronary events in hypertensive patients. Hypertension. 2002;39:10-15.

29. Levy D, Garrison RJ, Savage DD, Kannel WB, Castelli WP. Prognostic implications of echocardiographically determined left ventricular mass in the Framingham Heart Study. The New England Journal of Medicine.1990;322:1561-1566. 